\title{
A Review Study on Children's Awareness of Inconsistencies in Education and Its Impact on Child Development
}

\author{
Muhammed Ali Isik \\ European University of Tirana, Tirana/Albania \\ muhammedali77@hotmail.com
}

\begin{abstract}
Among widely known factors on instructional inconsistencies is the fact that school children are not always aware of them or they don't immediately recognize the logic behind them at the very beginning of the exposure. The reviewed article by Markman (1979) suggested that school children up to age 12 are not able to automatically recognize logical inconsistencies. The reviewed article mentioned such an unawareness of inconsistencies as a comprehension failure which should be studied in order to find strategies andlor methodologies that foster comprehension and avoid failure. The present study aims at reviewing the article by Markman on the topic of awareness in general, self-awareness and comprehension failure so as to search and find ways that would help school children`s development.
\end{abstract}

Keywords: inconsistency, instruction, awareness, comprehension failure, children development

\section{INTRODUCTION}

Studies conducted on child psychology in recent years increasingly started to focus on young children's abilities in understanding the language together with structural properties of the verbal language as they started to see the language as an object used for thought rather than having it simplified into a mere usage of making sentences. The research implemented on young children, especially the age group of 4 to 8 years, presented that there is a great manifestation of development in linguistic skills together with metalinguistic skills (e.g., de Villiers \& de Villiers, 1978: Donaldson, 1978; Hakes, Evans, \& Tunmer, 1980). In this regard, the article written by Markman (1979) complies with such findings as investigators suggest that linguistic awareness is one of the key elements of child development as well as helping the child to be self-aware when encountered with instructional or non-instructional inconsistency.

Even we as adults, there are many occasions or times that we go through confusion, unable to configure the things happening around us which make us feel that we have failed in comprehending things around us or a specific situation. However, this feeling of failure can turn into a strength if it can be considered as an awareness of the situation we are within as we start to make queries, try to find extra knowledge on the case, and process a kind of cognitive skills in order to reach understanding of the failure andlor the situation that caused perplex. This could be considered as a little trip that goes through insight as well. The second type of realization that comes from a more deliberate cognitive analysis and research of the case is intentional analysis of failure in realizing that we could not fully comprehend the previously gained experience or information and thus we failed. At this point Markman (1979) suggests that we use the required inferential processing as to have an influence on the child's ability of gaining awareness of the situation. The author aimed at understanding the effect of such a process and its necessities as a basis for school children's comprehension of inconsistencies and their self-realization of failure.

In the reviewed article the researcher is mainly proposing a self-realization of inconsistent comprehension as a failure. It is suggested that the inferential processing requirements and the nature of the standard should especially affect children's awareness of a problem. Subsequently, it is aimed to examine children's use of inconsistency as a basis for noticing their own comprehension failure. The second aim is to improve self-awareness by promoting more careful comprehension through probes used for explicit and implicit texts in three studies. 


\section{METHODOLOGY}

The primary source of the present study was the article written by Markman (1979) "Realizing That You Don't Understand: Elementary School Children's Awareness of Inconsistencies". As a secondary source the article written by Tunmer, W. E., Nesdale, A. R., \& Pratt, C. (1983). "The development of young children's awareness of logical inconsistencies" Following procedures were revised through these two articles: In the first study, twenty children (inadequate number of male and female) from each of grades 3,5 , and 6 (with their mean ages) of a public school; in study 2 and 3,32 third, 32 sixth graders (adequate number of male and female) from two different public schools with the mean ages of the third and sixth graders were served as subjects. Explicit and implicit texts were read to the subjects in order to monitor their comprehension of inconsistency, if not they would be given probes (1-12) to promote understanding of the inconsistencies. In order to reach comprehension, in study 2, different than study 1 , repetition was used; in study 3 different than the other studies the instructional manipulation was omitted, they were told of a problem before reading.

\section{CHILD DEVELOPMENT AND THE ROLE OF INCONSISTENCY STUDIES}

Theories on child development were mostly based on gradual evolvement of physical growth and cognitive progress. On the other hand, mechanisms that are included in evaluating or assessing child's comprehension were not investigated by psychologists in the past years. The questions like, what and how these mechanisms fail, or what makes them change through the nature of the problem and do they develop together with the child were mostly unanswered. Nevertheless, it is noteworthy to mention that theories of comprehension (e.g., Bransford, Barclay, \& Franks 1972; Bransford \& Franks 1971 that emphasize variant degrees or methods of processing the same material have been very helpful in studies of comprehension, inconsistencies, and failure. Some other studies on development suggested that the extension of average processed materials goes higher together with age (Paris \& Lindauer 1976; Paris \& Upton 1976).

One of the results of young aged children's not being able to process sufficient material while trying to understand the problem was suggested by Markman (1977) "as a failure to realize that they have not understood material." Coherence and consistency have been the two areas of developmental studies proposing that using either of them as a standard for evaluation or assessing understanding might be a challenge for younger children attending elementary school. The first thing to mention in this regard is that studies investigating prose comprehension of children manifested that they are not all the time aware of the patterns or structures of the texts (Brown \& Smiley 1977). The difficulty could be lying behind the fact that children's processing comprehension principles are mostly based on structural features of the texts given to them.

\section{PROCEDURE OF THE EXPERIMENT IN MARKMAN'S STUDY}

The experimenter, after introducing herself, tells the elementary school children in the class that she would try to write essays and short stories for them, but she would expect to consult children as she would be in need of their help in creating comprehensive essays. The children were also asked to recommend changes when they feel the need for it and that they think the essays would be more understandable. The children were randomly given one from two situations; however they were limited by having them in groups of adequate grade and gender. The two situations were explained to them as when they figure out a problem (or an inconsistency) they would rather determine if it was implicit or explicit. They were given a total number of three essays in balanced order. Essays were read three times to avoid missing points and help children's comprehension. They were expected to tell the experimenter when there was anything left out, unclear, and not easy to understand. The comprehension based on perceived organization is a basic element to better understand sentences, structures, paragraphs and texts. The scheme of using stories has long been used to explain processes of comprehension on young children and adults (Handler \& Johnson, 1977; Stein \& Glenn, 1978; Thorndyke, 1977).

\subsection{Results}

The results of the repetition condition were a replicate of the one in standard condition. On the other hand in the set condition there is a significant improvement in comprehension. Thus, it can be inferred that the greater the disparity between the amount of information processing required and the amount actually executed, the more subjects will be misled into thinking they have comprehended material they have in fact failed to comprehend. 
The scores in the article reviewed were given from 1 to 13 for each essay. The timing of realizing the inconsistency determined the score range of children. For example, 13 were given when the child did not ask any questions until encountered the real contradiction in the essay.

\subsection{Discussion}

The overall performance of sixth graders was better than the third graders through which can be surmised that biological age can also be a factor in comprehension. It was also stated that adults (college students) could easily infer the inconsistencies in the texts. The present study indicates important empirical study as it helps us to realize children may not automatically detect inconsistencies even though carefully processing material. So, we need to investigate more on how to improve self-awareness.

\subsection{Strong aspects of the study}

Although comprehension monitoring is a tough measurement to lead on, the researcher(s) brought up some reliable data through which we realize our incompleteness in understanding failure. Especially for elementary school teachers it serves valuable, valid, applicable methodology in teaching.

The explicit and implicit texts and the subjects used in this research can generalize the data for elementary school children. If the texts were of a more complicated extraction of a whole than results could be generalized for college students too.

\section{CONCLUSION}

The measurement tools were prose based and not numeric based, it would be interesting and it could serve valuable data if numeric measurements (math, physics etc.) were included.

The IQ level of the subjects is not known, if they could measure their levels before the monitoring they could be categorized with their levels, and the research could be more objective.

Self-awareness is very important to realize our surroundings with a better approach to inconsistencies as things we face with may indicate sub-meanings or implications that prevent us from failure.

\section{Elements of Further Study:}

Why are the tables not shown with percentages? A holistic table that would finalize the research would make it easier to see all three conditions as the pieces of a whole.

Were the subjects mentally ready for monitoring? Which school hours were used and, as the research is prose based, were they literature classes?

Why the subjects were not told to read the texts themselves? They could be given a certain amount of time or no time limitations. And they could have their answers to the probes in written formats as to have concrete materials.

In the set condition the subjects were told of a problem to have them mentally ready for the inconsistencies in the texts. What if they were told the same in a numeric, audio or a visual measurement tool? Would the results be the same?

\section{REFERENCES}

[1] Bransford, J. D., \& Franks, J. J. (1971). The abstraction of linguistic ideas.Cognitive psychology, 2(4), 331-350.

[2] Bransford, J. D., Barclay, J. R., \& Franks, J. J. (1972). Sentence memory: A constructive versus interpretive approach. Cognitive psychology, 3(2), 193-209.

[3] Brown, A. L., \& Smiley, S. S. (1977). Rating the importance of structural units of prose passages: A problem of metacognitive development. Child development, 1-8. 
[4] De Villiers, J. G., \& De Villiers, P. A. (1978). Language acquisition. Harvard University Press.

[5] Donaldson, M. (1978). Childrenl's minds.

[6] Mandler, J. M., \& Ritchey, G. H. (1977). Long-term memory for pictures.Journal of Experimental Psychology: Human Learning and Memory, 3(4), 386.

[7] Markman, E. M. (1979). Realizing that you don't understand: Elementary school children's awareness of inconsistencies. Child development, 643-655.

[8] Paris, S. G., \& Lindauer, B. K. (1976). The role of inference in children's comprehension and memory for sentences. Cognitive Psychology, 8(2), 217-227.

[9] Paris, S. G., \& Upton, L. R. (1976). Children's memory for inferential relationships in prose. Child Development, 660-668.

[10] Pratt, C., Tunmer, W. E., \& Bowey, J. A. (1984). Children's capacity to correct grammatical violations in sentences. Journal of Child Language,11(01), 129-141.

[11] Stein, N. L. (1978). How children understand stories: A developmental analysis. Center for the Study of Reading Technical Report; no. 069.

[12] Thorndyke, P. W. (1977). Cognitive structures in comprehension and memory of narrative discourse. Cognitive psychology, 9(1), 77-110.

[13] Tunmer, W. E., Nesdale, A. R., \& Pratt, C. (1983). The development of young children's awareness of logical inconsistencies. Journal of Experimental Child Psychology, 36(1), 97-108. 